\title{
РОЗПОДІЛ РЕСУРСІВ ІНФОРМАЦІЙНОЇ БЕЗПЕКИ В ДИНАМІЧНОМУ РЕЖИМІ
}

Розглянуто динамічний режим протистояння двох сторін в сфері інформаційної безпеки. Приведено приклади розрахунків системи з двох об'єктів з різними вразливостями і різним розподілом інформації на об’єктах. Розглянуто перехідний процес при досягненні сідлової точки та визначено інтервали її існування. Белман

Ключові слова: цільова функція, теорія ігор, сідлова точка, динамічний розподіл ресурсів, метод

Вступ. Протистояння двох сторін у сфері інформаційної безпеки відбувається в динамічному режимі [1,2]. Націленість атак з часом може змінюватись, супроводжуючись перерозподілом ресурсів нападу між об’єктами. Така ситуація виникає, зокрема, наприклад, при проведенні розвідки, коли напад не має відомостей про розподіл інформації на об'єктах і в результаті розвідки має можливість спрямувати свої зусилля у вигідному для себе напрямку. Перерозподіл ресурсів нападу викликає відповідну реакцію захисту, який також перерозподіляє свої ресурси. В цій ситуації виникає низка питань:

1) за яких умов існує сідлова точка для величини, яка визначається цільовою функцією і як на ії положення впливають умови протистояння - відносна кількість ресурсів нападу $(X)$ і захисту $(Y)$, розподіл інформації між об’єктами $g_{k}$ ( $k$ - номер об’єкта), вразливості $f_{k}$ об'єктів;

2) яким повинен бути розподіл ресурсів захисту в умовах невизначеності, у випадку, коли сідлова точка відсутня;

3) яким чином в ситуації, коли націленість стає відомою, перерозподілити інформацію між об'єктами так, щоб загальні втрати стали мінімальними;

4) як відрізняються алгоритми управління при використанні різних критеріїв оптимальності - таких, як критерії Севіджа, Гурвіца, Лапласа, Бейєса;

5) як вплине на кінцеві рекомендації по розподілу ресурсів використання різних цільових функцій, котрі визначають такі величини, як кількість вилученої інформації, прибуток від внесеної інформації, їх рентабельність і яким буде результат при використанні багатоцільової функції;

6) яким буде алгоритм управління при комплексному протистоянні, коли кожна 3 сторін витрачає одну частину ресурсів на захист інформації, а іншу - на здобуття інформації суперника.

Мета досліджень - дати відповідь на деякі 3 поставлених питань, що дозволить наблизитись до розробки методики оптимального управління захисту інформації в умовах протистояння, які можуть відрізнятися кількістю об'єктів, їх вразливістю, розподілом інформації між об'єктами.

Постановка задачі і методика розрахунків. Використаємо цільову функцію, яка визначає частку вилученої інформації, у вигляді [3]:

$$
i(x, y)=\sum_{k=1}^{l} g_{k} p_{k} q_{k}(x, y) f_{k}(x, y),
$$

де $k$ - номер об'єкта; $x$ і $y$ - ресурси нападу i, відповідно, захисту; $g_{k}$ - відносна кількість інформації на об'єкті; $p_{k}$ - імовірність нападу на об’єкт; $q_{k}(x, y)$ - щільність імовірності виділення нападом ресурсів $x$ при заданому значенні $y ; f_{k}(x, y)$ - імовірність вилучення інформації при даному співвідношенні $x$ і $y$, яку розглядаємо як динамічну вразливість об'єкта.

Застосовуючи метод динамічного програмування [4], будемо розглядати ситуацію, коли напад і захист почергово роблять кроки, розподіляючи свої ресурси оптимальним 
чином, тобто так, щоб досягти на кожному кроці нападу $i_{\max }$ i на кожному кроці захисту $i_{\min }$. Розподіл ресурсів протилежної сторони на кожному кроці вважається відомим. Загальна кількість ресурсів як нападу $X=\sum_{k=1}^{l} x_{k}$, так і захисту $Y=\sum_{k=1}^{l} y_{k}$ залишається незмінною, при цьому $Y=0,05$, а $X$ може змінюватись для різних систем, що призводить до зміни відносної величини $Z=\frac{X}{Y}$. В термінології теорії ігор це позиційна гра. У якості керуючої змінної обрано об'єм ресурсів нападу, що виділяється на перший об'єкт ( $\left.x_{k}\right)$, залишаючи на другий об'єкт $\left(X-x_{k}\right)$ ресурсів. Розрахунки виконано у Microsoft Excel із кроком 0,005.

Маючи на меті виявити вплив таких показників, як $g_{k}, i, f_{k}(x, y)$ на динамічний режим $i(n)$ ( $n$ - номер кроку), покладемо $p_{k}=1$ (напад відбувся) і $q_{k}(x, y)=1$ (залежність $q_{k}(x, y)$ слід враховувати при переході до стохастичної задачі). Розглядаючи систему з двох об'єктів, маємо спрощений вираз для цільової функції: $i(x, y)=g_{1} f_{1}(x, y)+g_{2} f_{2}(x, y)$.

Результати досліджень. Існування сідлової точки при заданому виді функцій вразливості $f_{k}(x, y)$ і співвідношення $\frac{g_{1}}{g_{2}}$ залежить від відносної кількості ресурсів $Z$. При використанні дробно-лінійних залежностей $f_{k}(x, y)$ сідлова точка існує при всіх значеннях $Z$. Якщо хоч одна із залежностей є дробно-нелінійною, то сідлова точка існує в певних інтервалах зміни $Z$, які для деяких функцій $f_{k}(x, y)$ приведені у табл. 1 та на рис. 1.

Знайдені інтервали $Z$ носять складний характер, так як залежать від величин $f_{k}(x, y)$, $x_{k}, y_{k}, g_{k}$, що вирізняються широким діапазоном можливих значень.

Перейдемо до розгляду динамічного режиму в оремих ситуаціях. Почнемо з випадку, коли сідлова точка відсутня.

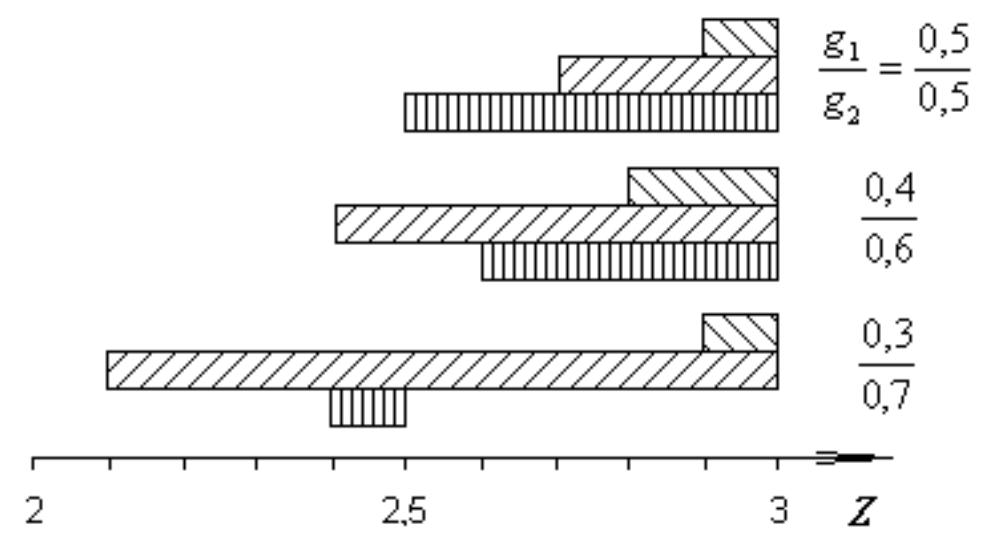

Рис. 1. Графічне зображення інтервалів існування сідлової точки:

向 -варіант 1, $\square$ - варіант 2, $\triangle$ - варіант 3

Інтервали існування сідлової точки

Таблиця 1

\begin{tabular}{|c|c|c|c|c|}
\hline \multirow{3}{*}{$\begin{array}{c}\text { № } \\
\text { варіанта }\end{array}$} & \multirow{3}{*}{ Вразливості об’єктів } & \multicolumn{3}{|c|}{ Інтервали значення $Z$} \\
\hline & & $\underline{g_{1}}=\underline{0,3}$ & $\underline{g_{1}}=\underline{0,4}$ & $\underline{g_{1}}=\underline{0,5}$ \\
\hline & & $g_{2} \quad 0,7$ & $g_{2}$ & $g_{2}$ \\
\hline
\end{tabular}




\begin{tabular}{|l|l|l|l|l|}
\hline 1 & $f_{1}=\frac{x_{1} / y_{1}}{x_{1} / y_{1}+8}, f_{2}=\frac{\left(x_{2} / y_{2}\right)^{2}}{\left(x_{2} / y_{2}\right)^{2}+16}$ & $2,4-2,5$ & $2,6-3$ & $2,5-3$ \\
\hline 2 & $f_{1}=\frac{x_{1} / y_{1}}{x_{1} / y_{1}+8}, f_{2}=\frac{\left(x_{2} / y_{2}\right)^{3}}{\left(x_{2} / y_{2}\right)^{3}+32}$ & $2,1-3$ & $2,4-3$ & $2,7-3$ \\
\hline 3 & $f_{1}=\frac{\left(x_{2} / y_{2}\right)^{2}}{\left(x_{2} / y_{2}\right)^{2}+16}, f_{2}=\frac{\left(x_{2} / y_{2}\right)^{3}}{\left(x_{2} / y_{2}\right)^{3}+32}$ & $2,9-3$ & $2,8-3$ & $2,9-3$ \\
\hline
\end{tabular}

На рис. 2 а приведено динамічний режим $i(n)$ і відповідні розподіли $x_{k}, y_{k}$ в системі, де $g_{1}=0,3 ; g_{2}=0,7 ; Z=1,2 ;$ функції $f_{k}(x, y)$ мають вигляд:

$$
f_{1}=\frac{x_{1} / y_{1}}{x_{1} / y_{1}+8}, f_{2}=\frac{\left(x_{2} / y_{2}\right)^{2}}{\left(x_{2} / y_{2}\right)^{2}+16} .
$$

Перший крок відповідає рішенню нападу. Розподіл $y_{k}$ вважаємо пропорційним співвідношенню $g_{k}$ на об'єтах. Використовуючи алгоритм методу Белмана, знаходимо розподіл ресурсів нападу, що забезпечує максимальну кількість вилученої інформації. Це варіант, за якого усі ресурси $X=Z \cdot Y=1,2 \cdot 0,05=0,06$ слід виділити на другий об'єкт 3 вищою відносною кількістю інформації.

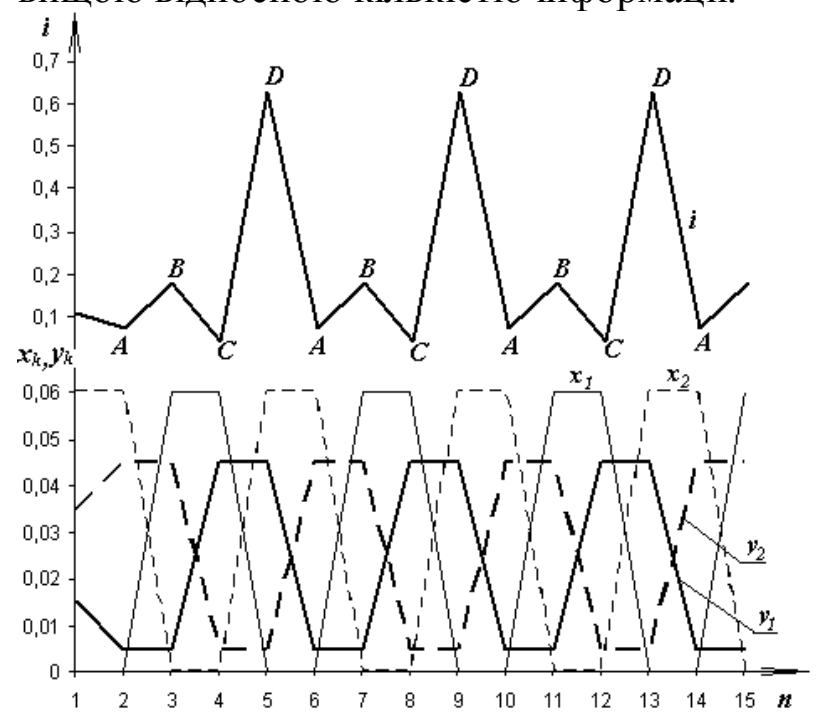

a)

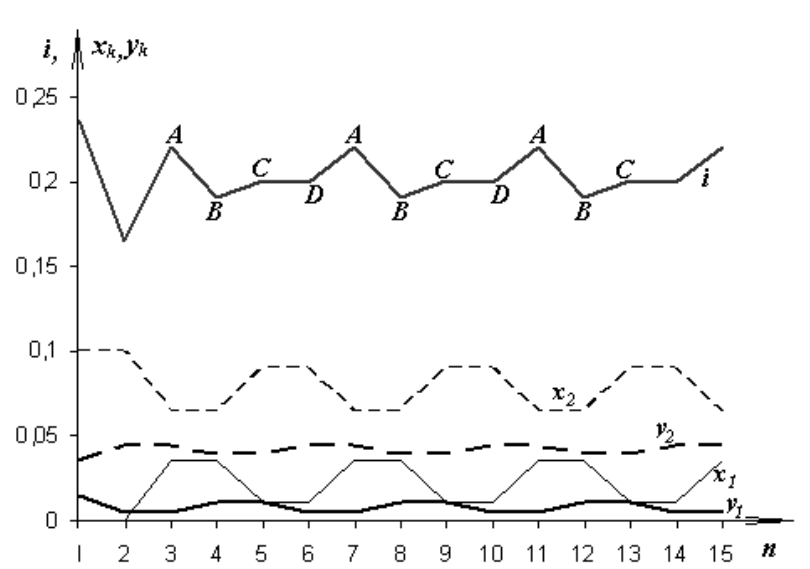

б)

Рис. 2. Динамічний режим протистояння при відсутності сідлової точки

На другому кроці, котрий виконує захист, знаходимо розподіл $y_{k}$, при якому за усіх можливих варіантів дій нападу кількість вилученої інформації буде мінімальною (на рис. 2a це відповідає значенню $i=0,06$ в точці $A$ при $n=2)$. Такий розподіл передбачає, що мінімальну неподільну частку ресурсів $y_{k}=0,005$ (у разі $y_{k}=0$ усю інформацію $3 k$-го 
об’єкту буде вилучено) необхідно виділити на перший об'єкт, на якому $x_{1}=0$, а решту ресурсів вкласти у другий об’єкт, де $x_{2}=X=0,06$. На наступному кроці нападу максимальна кількість вилученої інформації досягається в точці $B$ при розподілі, за якого усі ресурси $X$ виділено на перший, найменш захищений об'єкт. Враховуючи, що $g_{1}=0,3$, одержуємо $i_{\max }=0,18$.

На четвертому кроці захисту алгоритм пропонує мінімальну частину ресурсів залишити на другому об'єкті, а решту виділити на перший, при цьому кількість вилученої інформації зменшиться до $i_{\text {min }}=0,04$ (точка $C$ на рис. 2a). Однак, таке рішення являється ризикованим з огляду на те, що на наступному кроці напад переходить у точку $D$ на рис. 2 a та $i_{\max }$ досягає значення 0,63 . Зростання $i_{\max }$ пояснюється тим, що напад знову усі ресурси направить на другий, більш важливий об'єкт, який до того ж являється найменш захищеним.

3 рис. 2а можна зробити висновок, що захисту необхідно розподілити свої ресурси між об'єктами наступним чином: $y_{1}=0,005 ; y_{2}=0,045$. При цьому кількість вилученої інформації за будь-яких умов не перевищить значення $i_{\max }=0,18$, що відповідає точці $B$ на рис. $2 \mathrm{a}$.

Із збільшенням Z у нападу з'являється можливість розподілити свої ресурси між двома об'єктами, а не зосереджувати їх на одному з них, як це було у попередньому випадку, і при цьому вилучити більше інформації. Це ілюструє рис. 2б, де показано динамічний розподіл ресурсів при $Z=2$. Різниця між $i_{\min }=0,19$ та $i_{\max }=0,22$ зменшилась, як і величина співвідношення ресурсів нападу $\frac{x_{1}}{x_{2}}$ і захисту $\frac{y_{1}}{y_{2}}$ на об'єктах.

Рис.3 ілюструє динамічний режим при при $Z=2,5$, коли сідлова точка вже існує.

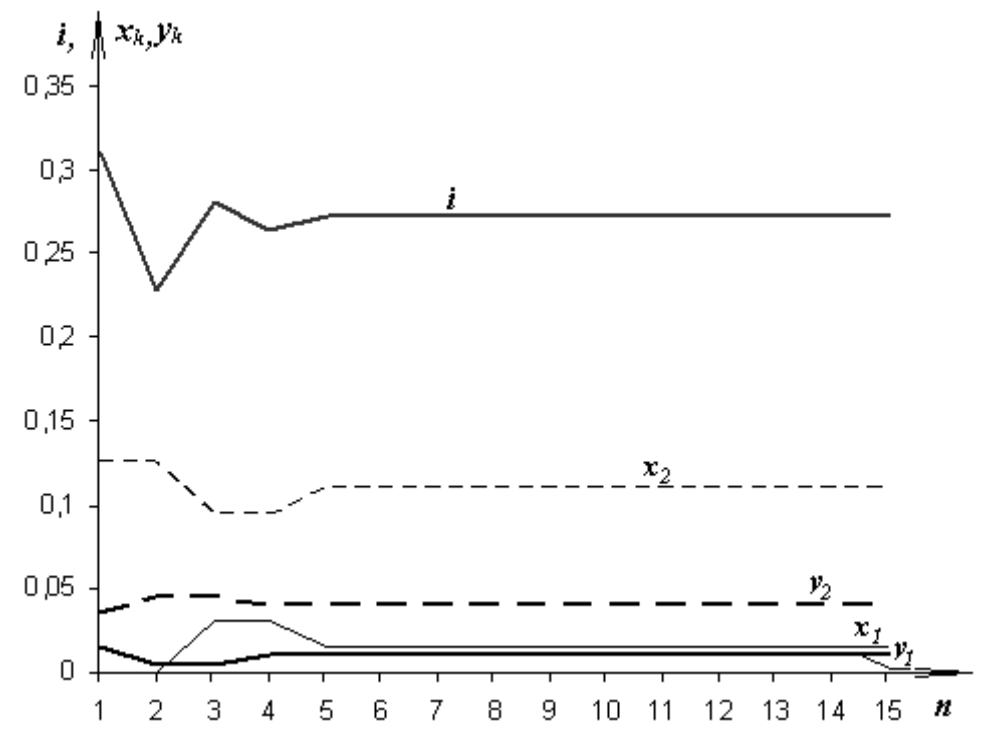

Рис. 3. Процес досягнення сідлової точки

Тривалість перехідного процесу $N_{\Pi}$ залежить від того, наскільки вдалим обрано початковий розподіл, тобто наскільки близьким до $i_{\mathrm{c}} \in$ початкове значення $i$.

Сідлова точка реалізується при наступному розподілі ресурсів: $y_{1}^{0}=0,01 ; y_{2}^{0}=0,04$; $x_{1}^{0}=0,015 ; x_{2}^{0}=0,11$ При цьому кількість вилученої інформації становить $i^{0}=0,27$. Ця точка $є$ оптимальною для обох сторін: відхилення від $x_{k}^{0}$ приводить до зменшення $i$, а відхилення від $y_{k}^{0}$ - до його збільшення. 
Висновки. Головним завданням економічного менеджменту інформаційної безпеки $є$ розробка оптимальної стратегії, тобто визначення при заданій кількості ресурсів захисту їх оптимального розподілу між об'єктами. Кращим варіантом $\epsilon$ розподіл, який відповідає сідловій точці. Цей варіант гарантує одержання певних граничних показників, оскільки нападу також не вигідно відступати від сідлової точки. При відсутності сідлової точки загальної оптимальної стратегії не існує: оптимальний розподіл залежить від кількості і розподілу ресурсів нападу і розраховується при досягненні екстремального значення цільової функції в кожному окремому випадку. Для досягнення режиму сідлової точки при побудові інформаційної системи слід прагнути до того, щоб відмінності між об'єктами (як по кількості зосередженої інформації, так і по вразливості) були по можливості меншими. При заданих розподілах наявність сідлової точки визначається величиною $Z$. Таким чином, відомості про суперника, необхідні при побудові оптимальної системи захисту - це оцінка ресурсів $X$, які він може виділити на здобуття інформації.

\section{ЛІТЕРАТУРА}

1. Tatsumi K. Optimal timing of information security investment: A real options approach / K. Tatsumi, G. Makoto // WEIS 2009, University College of London. - July 21, 2009.

2. Bohme R. The Iterated weakest link: A model of adaptive security investment / R. Bohme, T. Moor // WEIS 2009, University College of London. - June 24, 2009.

3. Левченко Є.Г. Оптимізаційні задачі менеджменту інформаційної безпеки / Є.Г. Левченко, А.О. Рабчун // НТЖ Сучасний захист інформації. - 2010. - №1. - С. 16-23.

4. Беллман Р. Динамическое программирование. - М.: ИЛ, 1960. - 400 с. 